Academic Integrity and Plagiarism:

A Review of the Influences and Risk Situations for Health Students

Hai Jiang ${ }^{1}$

Lynne Emmerton ${ }^{1,2 *}$

Leigh McKauge $^{1}$

1 The University of Queensland

School of Pharmacy

Brisbane, Australia

2 Curtin University

School of Pharmacy

Curtin Health Innovation Research Institute

*Corresponding author:

Dr Lynne Emmerton

School of Pharmacy

The University of Queensland Qld 4072

Australia

Email: 1.emmerton@pharmacy.uq.edu.au 


\title{
Academic Integrity and Plagiarism: A Review of the Influences and Risk Situations for Health Students
}

\begin{abstract}
There is increasing focus among the health professions on the development of integrity and professionalism in students of Health disciplines. While it is expected that Health students will develop, and commit to, the highest standards of conduct as undergraduates and henceforth through their careers, the pressures of assessment and external commitments may lead to both unintentional and intentional plagiaristic behaviours. Exponential growth in Internet resources and new information technologies, as well as individual belief systems or naivety about the authorship attribution convention, suggest complexity in understanding the risks and factors associated with academic plagiarism. This paper reviews the education literature to provide an insight for academics into reasons for student plagiarism and, where possible, management of these risks. Our review refers to the health professions as a discipline in which academic conduct in students should be at the highest possible standard.
\end{abstract}

Keywords: Academic integrity; Health Sciences; Plagiarism; Professionalism

\section{Introduction}

According to the Chambers Dictionary of Etymology, the word 'plagiarism' is derived from the old English word 'plagiary', which means to "wrongfully take another's words or ideas" (Barnhart, 1988, p.801. The source of the word 'plagiary' originated from the Latin words plagarius (murderer, seducer, plunderer, literary thief), plagium (kidnapping) and plaga (snare, net) (Barnhart, 1988). Plagiary was recognised as literary theft as early as the seventeenth century (Mallon, 1989). As Park (2003, p.473) stated, "Copying from other writers is probably as old as writing itself, but until the advent of mass-produced writing, it remained hidden from the public gaze."

Plagiarism has been further defined as "stealing the words or ideas of someone else and passing them off as one's own without crediting the source", and "a theft of words or ideas beyond what would normally be regarded as general knowledge" (Park, 2003, p.472). These definitions concurred with that by Bilic-Zulle et al. (2005, p.126; 2007, p.140 ), who described plagiarism as "misappropriation of another person's ideas, methods, results or words, i.e. using the intellectual property of another person without giving appropriate credit".

Despite this apparent consistency in the definition of plagiarism, there may be some operational differences. For example, in a study by Honny et al. (2009, p.251), conducted in a Dental School, plagiarism was aligned with cheating, an action stated as "using someone else's words, work, test answers, and/or ideas and claiming them as your own". This is a relatively narrow definition compared with that of Bilic-Zulle et al. Harper (2006, p.673), from the School of Nursing, University of Central Florida, maintained a broader definition by describing plagiarism simply as "the failure to reference another's work". It is unclear whether such definitional differences are specific to disciplines or institutions.

While the concept of plagiarism is not new, there has been increased focus in recent years on identification of methods for conducting plagiarism, along with measurement 
of its prevalence and new modes of detection. While it is widely recognised that the prevalence of plagiarism is underreported (Gaberson, 1997; Teplitsky, 2002; Park, 2003; Carroll, 2004; Rabi et al., 2006; Scanlan, 2006; Kisamore et al., 2007, 2009; Hutchins \& Cobb, 2008; Staats et al., 2008; McCabe, 2009; Postle, 2009), it could be argued that determining its prevalence should be secondary to understanding the rationale, risk situations and factors associated with this behaviour.

Disciplines of particular interest are the health professions, where expectations of specific professions relating to integrity, trustworthiness, honesty and professional standards are well established through codes of professional conduct, codes of ethics, competency standards and professional practice standards. Recently in Australia, the formation of a national professional registration body, the Australian Health Practitioner Regulation Agency (AHPRA, 2010), has introduced mandatory registration of students of the health professions (along with new expectations and requirements for students' conduct as future health professionals, and reporting of breaches of professional behaviour (Parker et al., 2010). The concept of academic integrity is integral to these expectations and to the conduct of students training in the health professions. The underlying premise of this paper is that, as future health practitioners, students of the health professions should be expected to conduct themselves according to the highest possible standards of academic integrity, and thereby recognise and resist risks and temptations relating to plagiaristic behaviour.

This paper draws on literature in the field of tertiary education, not specific to but particularly in the health professions, to provide an overview of the reasons that students commit, or might commit, plagiarism, and the risks and circumstances that have been reported to lead to these behaviours. Our aim is to encourage academics to understand the 'how' and 'why' of plagiarism, and apply this knowledge to instil in students a high level of appropriate academic practice. Where possible, references directly relating to plagiarism have been used, but we have considered 'plagiarism' as a form of 'cheating' and 'academic misconduct', and some of the relevant literature has used these terms interchangeably. Deliberate cheating, however, may only be aligned with intentional plagiarism, as opposed to unintentional plagiarism, which is a consequence of naivety regarding appropriate citation of others' work.

Literature was identified using Pubmed, Science Direct, Elsevier, Springer, JSTOR and Wiley databases, with contemporary papers (1999 or more recent) favoured, apart from those establishing the terminology of this field. Search terms included "academic cheating", "plagiarism", "student", "health" or "health sciences" and "student". Over 100 abstracts were identified and categorised. Approximately 65 papers relevant to the prevalence of cheating/plagiarism, reported modes for committing plagiarism, definitions and factors associated with academic integrity (either in commentaries or research reports) were retained for review. Sections of the papers were systematically coded, and the content integrated and critiqued in this review. 


\section{Factors Associated with Academic Misconduct by Students}

Age

The association between age and plagiaristic behaviour has been studied in the United States of America (USA) and Europe, although there is no consistency in the literature as to the nature of this association. Norwegian research conducted by Kisamore et al. (2007) explored the relationship between individual and social factors influencing students' perception of academic misconduct. The authors proposed that mature-age students were less likely to consider performing acts of academic misappropriation, and were keener to report acts of cheating than younger students. These results concurred with research conducted by Straw (2002), Hardigan (2004) and Simon et al. (2004), who revealed that older students typically had a more conservative attitude towards cheating. Honny et al. (2009), however, reported age as having a negative relationship with plagiarism, due to a reduction in self-reported academic violations with increasing age.

Sex

The literature also revealed that the relationship between students' biologic sex and academic integrity is largely debateable (McCabe et al., 2001a; Elzubeir \& Rizk, 2003; Park, 2003; Rennie \& Rudland, 2003; Bolin, 2004; Hrabak et al., 2004; Simon et al., 2004; Austin et al., 2006; Harper, 2006; Rabi et al., 2006; Andrews et al., 2007; Kisamore et al., 2007; Staats et al., 2008; Honny et al., 2009; McCabe, 2009; Wilkinson, 2009). Early research by Bowers (1964) pointed to a higher prevalence of male students in cases of cheating. Multi-centre studies in the United Kingdom (UK) and the USA also found male students were more likely to commit acts of academic plagiarism compared with females (Aggarwal et al., 2002; Straw, 2002; Hrabak et al., 2004); however, these results were challenged by Simon et al. (2004), who proposed a recent increase in the number of women engaging in academic misconduct. This latter study revealed that over half of the female students interviewed did not self-report academic misconduct.

Findings from the Center for Academic Integrity (2005) in the USA also took a similar stance. This national research report found that females cheated as commonly as male students, and were more likely to do so in a male-dominated environment. Analysis by Kisamore et al. (2007) also described similar trends with Business students. A different point of view, as proposed by McCabe et al. (2001a), was that differences in self-reported cheating by both sexes were minimal. This concept was also reported by Rennie \& Rudland (2003) and McCabe (2009).

\section{Education}

Variability between undergraduate and postgraduate students in the perception of academic misconduct has not been widely researched in the academic field (Park, 2003). Early research by Bowers (1964) suggested a higher level of academic dishonesty reported from undergraduate students compared with postgraduate students. Generally, later work has agreed with Bowers' findings (McCabe et al., 2001a; Park, 2003; Rabi et al., 2006; Andrews et al., 2007; Kisamore et al., 2007; Hutchins \& Cobb, 2008; Honny et al., 2009; Ryan et al., 2009; Wilkinson, 2009). 
Rabi et al. (2006) pilot-tested research on Pharmacy students' perceptions of academic dishonesty, and found that students who had completed a degree prior to Pharmacy were less likely to cheat compared with first-year students who had recently graduated from high school. The authors explained this as a product of graduate students' maturity and their commitment to their future career. This was supported by McCabe \& Trevino (1997), who found an inverse relationship between education level and reports of academic violation. Kisamore et al. (2007) detailed similar findings, in that there was a higher likelihood for postgraduate students to report cases of cheating.

The relationship between year levels of undergraduate student education and academic dishonesty were also investigated by Rennie \& Rudland (2003). This Scottish cross-sectional study employed a 461-student survey based on individual scenarios of hypothetical situations to test students' ability to recognise unethical academic behaviour. The authors found that most first-year students perceived numerous acts of plagiarism as fair, perhaps due to students' naivety or lack of experience in dealing with such situations.

Brown (1995) accepted that a difference in the understanding of academic integrity seemingly existed between older, experienced postgraduate and young undergraduate students; however, graduate Business students in this study demonstrated a similar level of unethical academic behaviour when compared with undergraduate students of other disciplines. Data from Hrabak et al. (2004) also entailed an inverse relationship between experienced students and academic integrity.

It is reasonable to assume a correlation between years spent in study and increasing age of the student. Further study of both age and years in study would elucidate the degree of confounding.

\section{Honour Codes}

Simon et al. (2004, p.78) described honour codes as "one of the most visible methods of promoting active student involvement in and responsibility for the maintenance of academic honesty." Numerous studies have explored the correlation between academic integrity and the existence of honour codes. Results from these studies generally indicate that students from universities with a strict honour code (via public declarations for academic integrity or signing an honesty pledge) have fewer cases of reported plagiarism compared with universities that do not have such statements (McCabe et al., 2001a, 2001b, 2002; Simon et al., 2004; Harper, 2006; Scanlan, 2006; Staats et al., 2008; Honny et al., 2009).

However, it is also generally agreed amongst academics that honour codes alone do not necessarily enhance academic integrity (McCabe et al., 2001a, 2001b, 2002, Simon et al., 2004; Staats et al., 2008). The effectiveness of honour codes is purportedly enhanced when the responsibility for detection is shifted from administration and staff to students; this approach encourages all students to take a role in maintaining a sound academic environment for their peers (McCabe et al., 2001b, 2002; Simon et al., 2004). Students who learn in this environment will accept the social norm of fair work, and, in return, be less likely to commit academic misbehaviour (McCabe et al., 2001a, 2001b, 2002). The study conducted by McCabe 
et al. (2001b) also described students in an honour-code system to be more aware of the importance of academic integrity and more open when talking about the issue of plagiarism.

Some studies did not support the use of honour codes to decrease the incidence of cheating. For example, research by Honny et al. (2008) in Dental Hygiene students in the USA failed to find a significant relationship between the existence of an honour code and self-reported academic plagiarism. Muhney et al. (2008) reported similar results, while McCabe et al. (2001a) proposed that students bound by an honour code may not overcome academic pressures or face other influences to cheat, and thus are more likely to cheat than those in non-honour-code systems. Scanlan (2006) contended that students in honour-code systems continue to conduct plagiarism because authorities have failed to reinforce the contextual norm and act on those who had cheated. The validity of both arguments warrants further exploration.

\section{Academic Integrity Awareness Initiatives}

Many commentators on academic integrity have supported the use of training modules or curriculum in academic integrity, under the premise that "the best way to diminish academic misconduct is to prevent it" (Scanlan, 2006). Despite general support for such training, little evidence exists in terms of its effect on academic behaviour, and it is assumed that these initiatives are an attempt to model academic 'best practice' to encourage students to take responsibility for their actions. Indeed, Carroll (2004) argued that training about expected academic behaviour can do little more than "alert students to their responsibilities", rather than teaching them the requisite skills.

One initiative to train students in best practice was reported as a discussion of cheating and plagiarism issues at an assembly of Nursing students (Solomon et al., 2000); the effectiveness of this was not measured, and would be unrealistic to measure. This type of initiative could be considered both 'training' and 'warning'. Similarly, Postle (2009), a Social Work educator, described the use of a voluntaryattendance student workshop to share information and discuss reasons for plagiarism, along with strategies for detection and deterrence. Again, the impact of this type of initiative was not reported., and although the workshop attracted low attendance, it cannot be assumed that mandating attendance would enhance the outcomes of the training.

The concept of raising awareness about expected behaviour can be extended to publicising warnings about the consequences of breaching these expectations. BilicZulle et al. $(2005,2007)$, in a study testing the effect of an explicit warning against plagiarism, claimed that the warning was not effective: "students who were warned took the task more seriously, but not seriously enough to stop plagiarising." Reminders about the consequences of misconduct, including plagiarism, were recommended by Hutchins \& Cobbs (2008) as part of a structured formal course on ethics and professionalism; this was a recommendation from related research, but not investigated as a potential influence on misconduct rates. In summary, while the effects of proactive approaches to reducing plagiarism are largely unsubstantiated, these approaches remain as assumed deterrents to encourage appropriate academic behaviour. 


\section{Individuals’ Morals/Beliefs}

Honour codes may influence students' beliefs about plagiarism, and some confounding between these factors is expected. Considered separately, however, students' perception of academic integrity has been recognised as a key factor that influences the decision to cheat (Zobel \& Hamilton, 2002; Park, 2003; Rabi et al., 2006; Bilic-Zulle et al., 2007; Kisamore et al., 2007; Hutchins \& Cobb, 2008; Arhin \& Jones, 2009; McCabe, 2009; Postle, 2009; Ryan et al., 2009). Roberts and Rabinowitz (1992) described students' perception of cheating as dependent on factors such as need, provocation, opportunity and intentionality. Most plagiarism may occur because students perceive this as a minor offence compared with cheating in exams (Park, 2003; Hutchins \& Cobb, 2008), and, when given the opportunity, cannot resist the temptation (Park, 2003; Rabi et al., 2006; Kisamore et al., 2007; Postle, 2009). Gullifer \& Tyson (2010, p.470), in a series of focus groups with students of different programs and years of study, proposed a link between "limited exposure to learning about plagiarism" and unintentional plagiarism, with insufficient understanding appropriate citation practices leading to confusion and anxiety about being caught inadvertently plagiarising others' work.

Self-justification of such misconduct includes perpetrators" "neutralisation" of the behaviour due to their perception that it is common, beliefs that there is a low risk of being caught and the benefits outweigh the risks, refusal to work on assignments on their own accord, and not caring for the consequences of being caught (Zobel \& Hamilton, 2002; Park, 2003; Rabi et al., 2006; Staats et al., 2008; McCabe, 2009; Gullifer \& Tyson, 2010). In addition, Postle (2009) postulated that the severity of plagiarism is played down by students, due to its high occurrence.

A number of researchers have established that many students acknowledge the prevalence of cheating around them, but choose not to report incidents (Rabi et al., 2006; Scanlan, 2006; Kisamore et al., 2007; Honny et al., 2009; McCabe, 2009). This may be related to students' fears of being negatively perceived by peers, as explained above. Zobel and Hamilton (2002, p.24) stated that students regard actions such as copying phrases directly from the Internet, and trading ideas and answers between peers, as "normal and easy". Further, most students indicated that forming a group before an individual assessment to 'work as a team' is "reasonable and ethical".

A contrasting report of student perceptions was presented by Ashworth et al. (1997), in that academic perception among British students was significantly associated with a strong moral backbone, and students' value for friendship, trust and good learning outweighed the need for inappropriate behaviour. The validity of this research in the contemporary context, however, is questionable and calls for further research.

There is a lack of research in this field drawing on the morals and beliefs of Health students, who are expected (and indeed, required, at least in Australia) by their respective professions to attain and practise a high standard of professional conduct before entering community service (Thompson et al., 2008). Health faculties aim to proactively develop students' understanding and enforcement of professionalism via the curriculum (Thompson et al., 2008). Whether these efforts have impacted positively on students' perceptions of academic integrity and their misconduct behaviours remains unknown. 


\section{Culture}

The British study by Carroll (2004) suggested that plagiarism by international students is often over-represented in Western universities, based on the proposition that students from a non-English speaking background have often never had to write an essay independently. Many of these students acknowledged the existence of plagiarism rules, but failed to fulfil requirements because they were unsure of how to comply (Carroll, 2004).

Park (2003) also found a difference in attitudes between native and non-English speakers towards appropriate attribution of others' work. Further, since most international students often cope with more stress both socially and academically than native students, they may be more prone to cheat (Park, 2003). Zobel and Hamilton (2002) discussed the effect of cultural differences between Western and Oriental countries, making a point that students may originate from a country where using other people's words in their own assessment demonstrates understanding and application of knowledge.

The above research regarding students' cultural backgrounds appears to dichotomise students according to terms such as 'domestic versus international', 'Western versus Oriental', and 'native English speakers versus non-English-speaking background'. There were no published studies exploring the relationship between language proficiency and the incidence of plagiarism, cheating or other academic integrity breaches. Such research would be a useful insight into students' ability to articulately paraphrase written work without plagiarising, in addition to their understanding of academic practices for referencing the work of others.

\section{Technology}

In the past decade, development in micro-technology has made communication devices more compact, and most of all, affordable (Park, 2003; Carroll, 2004; Harper, 2006; Rabi et al., 2006; Scanlan, 2006; Kenny, 2007; Eastman et al., 2008; Hutchins \& Cobb, 2008; Staats et al., 2008; Arhin, 2009; McCabe, 2009; Postle, 2009; Roberson, 2009). Mobile telephones, laptop computers, portable data assistants, cameras and calculators are all devices commonly employed for academic misconduct (Harper, 2006; Langone, 2007; Arhin, 2009; Arhin \& Jones, 2009).

The most common source of cheating originates from inappropriate use of Internet material (Zobel \& Hamilton, 2002; Park, 2003; Carroll, 2004; Harper, 2006; Rabi et al., 2006; Scanlan, 2006; Kenny, 2007; Langone, 2007; Eastman et al., 2008; Arhin, 2009, Arhin \& Jones, 2009; McCabe, 2009; Postle, 2009; Mirza \& Staples, 2010). Its ease of access, along with enormous supply of information, allows the Internet to become the primary source whereby students might use the work of others without appropriate credit (Park, 2003; Carroll, 2004; Harper, 2006; Rabi et al., 2006; Scanlan, 2006; Kenny, 2007; Hutchins \& Cobb, 2008; Arhin \& Jones, 2009; McCabe, 2009; Postle, 2009). As Park (2003, p.481) explained, "the Internet provides unparalleled temptation and almost unrestricted opportunities for students to cheat". Park also described Internet plagiarism in the same psychological context as "using and finding free objects". 
Recent research undertaken by McCabe (2009) in the USA revealed that over $87 \%$ of the surveyed university students acknowledged the Internet as their primary source of plagiarism. Both Nursing faculty and non-faculty sources in McCabe's research also stated that 'copy and pasting' from the Internet was the most popular technique (McCabe, 2009).

Bilic-Zulle et al. (2005) conducted an experiment involving Medical students completing an assessment given accessible sources of data and no consequences for plagiarism. The majority of students in this situation would reportedly choose plagiarism as their first option.

The Center for Academic Integrity (2005) found that $40 \%$ of 50,000 students selfreported committing plagiarism, and $77 \%$ of students perceived that copying and pasting information from the Internet was not a serious academic breach. Similarly, over $48 \%$ of students who participated in Rabi et al.'s research admitted to copying, or witnessing students copying, directly from the Internet without appropriate referencing (Rabi et al., 2006). Several years earlier, Carroll (2004) suggested that Internet plagiarism was not a significant problem, with evidence of only two cases out of 1770 randomly selected from Turnitin ${ }^{\circledR}$ reports were over $75 \%$ plagiarised. The extensive plagiarism was reportedly unintentional, and mostly due to students' lack of knowledge of the appropriate citation technique. The contribution of technology to plagiarism requires further investigation, as it is unclear as to how 'intention' can be accurately determined. Further, whether plagiarism of online materials has increased in incidence in more recent years is unconfirmed, albeit suspected.

Online "paper mills" and essay websites are also of concern with technology advancement (Park, 2003; Scanlan, 2006; Kenny, 2007; Postle, 2009; Roberson, 2009; Ryan et al., 2009; Wilkinson, 2009). Papers electrically-generated online can be purchased or downloaded free of charge and are promoted with slogans such as "nonplagiarised" and "so you can get done and get on with your life" (Carroll, 2004, p.4; Harper, 2006; Scanlan, 2006). Both the risk and opportunity to use online sources are increasing as the available 'pool' online multiplies.

A recent trend in tertiary education is the use of online learning (McCabe, 2009; Mirza \& Staples, 2010). The use of online assessments, in particular, has offered convenience for students and assessors, yet the absolute validity and fairness of these assessments are concerning (Zobel \& Hamilton, 2002; McCabe, 2009; Mirza \& Staples, 2010) where there exists mechanisms for copying existing online material for assessment.

It should be noted that although the rapid development of electronic communications has created another platform for student plagiarism, it is this same platform that serves as the basis for the collection and detection of academic cheating (Park, 2003; Staats et al., 2008). Software such as Turnitin ${ }^{\circledR}$ is now employed in most universities to detect potential plagiarism (Park, 2003; Kenny, 2007). Park (2003, p.482) has stated that "the availability and accessibility of the Internet can be considered a "doubleedged sword" for those students engaging in plagiarism, as it can equally be used to detect the practice as well as conduct it". 


\section{Pressure}

Much research conducted within the last decade has focused on pressures on the individual as the driving force for academic misconduct (Park, 2003; Carroll, 2004; Rabi et al., 2006; Kenny, 2007; Kisamore et al., 2007; Hutchins \& Cobb, 2008; Postle, 2009; Gullifer \& Tyson, 2010). Contributing factors include time management, peer pressure and academic ability.

Time plays an important role in academic performance, especially for those with an active social life (Park, 2003; Hrabak et al., 2004; Postle, 2009; Wilkinson, 2009). Students who regularly participate in social activities often do not spend a great amount of time studying, tempting them to find an 'easy way out' in assessments (Park, 2003; Bolin, 2004; Honny et al., 2009; Wilkinson, 2009). Carroll (2004) and Kenny (2007) also suggested that time constraints may also be a consequence of students' commitment to paid work and family management, and poor organisational skills.

The academic capability of students to complete a set or multiple sets of tasks within a limited timeframe is another factor associated with plagiarism (Park, 2003; Carroll, 2004; Honny et al., 2009; Postle, 2009). Students who choose to plagiarise may be overloaded with assignments and tests at a specific point in time. Some students may have genuinely attempted the assessment, but have trouble meeting the deadline, while others leave assignments to the 'last minute', and as a desperate measure, choose to make a 'leap of faith' (Elzubeir \& Rizk, 2003; Park, 2003; Carroll, 2004; Hrabak et al., 2004; Kisamore et al., 2007; Honny et al., 2009; Postle, 2009). Students who cheat to improve or maintain their grade were also noted (Straw, 2002; Park, 2003; Hrabak et al., 2004; Rabi et al., 2006; Kisamore et al., 2007; Hutchins \& Cobb, 2008; Postle, 2009). For example, Straw's research found that students with a lower Grade Point Average (GPA) tended to have a higher rate of academic misconduct compared with those with a higher GPA (Straw, 2002). More significant intention to cheat by higher achievers, on the other hand, was found in reports by Bolin (2004), Rabi et al. (2006), Andrews et al. (2007), Kisamore et al., (2007) and Postle (2009).

Hrabak et al. (2004) however, did not find any correlation between GPA and intention to plagiarise. The lack of relationship may be partially explained by differences in cultural perception, what students perceive as acceptable behaviour and the consequences of detection of cheating/plagiarism (Hrabak et al., 2004). More research is recommended to establish further evidence for this possible correlation.

The influence of peer behaviour on academic misconduct has been widely documented in the literature (Andrews et al., 2007; Bolin, 2004; Eastman et al., 2008; Harper, 2006; Honny et al., 2009; Park, 2003; Rabi et al., 2006; Roberson, 2009; Wilkinson, 2009). Andrews et al. (2007, p.1036) summarised the contemporary viewpoint of students on academic integrity: "Students learn that it is no longer 'I win/you lose', but everyone wins or everyone loses". Most studies proposed that peer pressure can compel students to cheat to maintain friendships, to stay in mainstream society, and for fear of social accusation and rejection (Park, 2003; Rabi et al., 2006; Andrews et al., 2007; Honny et al., 2009). Early research conducted by Bowers (1964) found students employed peers' cheating behaviour as their own justification to cheat. A survey of 824 Business students by Chapman (2004) revealed that three-quarters of 
the students would consider cheating if their good friends were also involved. However, this outcome would theoretically reduce to $45 \%$ if an acquaintance were involved.

Research conducted by McCabe et al. (2001a, 2002) found the cheating behaviour of peers acts as an emotional support in cheating. His later studies suggested peer perception as also the most important parameter for academic misconduct, regardless of whether an honour code exists (McCabe et al., 2002). Harper (2006) also demonstrated in his study that peer behaviour can be of stronger influence than personal motivations when deciding to cheat.

\section{Scope of the Problem}

Academic integrity has been a focus of study over the past 20-30 years (Dick, Sheard \& Markham, 2001; McCabe, Trevino \& Butterfield, 2001; Kiehl, 2006; Scanlan, 2006; Kisamore, Stone \& Jawahar, 2007; Langone, 2007; Hutchins \& Cobb, 2008; Arhin, 2009; Gullifer \& Tyson, 2010). Despite the establishment of some generally accepted factors associated with plagiarism, others, such as age, sex, tertiary study experience, the existence of an honour code and individuals' morals or beliefs, are still debated in the literature (Parker et al., 2010). The inconsistency may be setting or discipline specific.

Several inherent limitations in the literature were noted. Firstly, there remains a lack of distinction between the concepts of 'plagiarism' and 'cheating' in many studies. 'Cheating' infers an intentional behaviour, yet it was established above that a proportion of plagiarism cases are unintentional, from naivety about authorship attribution conventions. The literature does not appear to refer to 'unintentional cheating', although it is commonly argued all plagiarism constitutes a form of cheating.

Secondly, the majority of studies did not measure students' perceptions of, or beliefs about, plagiarism, which may be considered indicators of their behavioural intention, if not their actual behaviour. It should also be recognised that self-reported behaviour is only a proxy measure of actual behaviour, and is susceptible to 'social acceptability' bias. Measurement of actual plagiaristic behaviour is unfeasible, unless based on case reports that explore the nature of the copying, supported by explanation by the perpetrator of the reasons behind the breach. Further research is required into students' perceptions and understanding of appropriate and inappropriate academic practices, and the relationship between perceptions, behavioural intention, actual behaviour and self-report of behaviour.

Thirdly, a range of factors contributing, or potentially contributing, to plagiaristic behaviours was identified above. There is a lack of multivariate analysis in the literature; this analysis would determine the relative dominance of factors, as well as explore the suspected correlation or confounding between factors.

Fourthly, in the health professions, academic integrity amongst students would be expected to be exemplary. The available studies spanned Dentistry, Nursing, Medicine and Pharmacy. On balance, there was limited insight into standards of academic conduct in these disciplines, and more broadly, within Health students. This 
highlights the need for further research in the Health disciplines, particularly given the developments relating to professional registration of Health professional students and focus on their development of ethical conduct during undergraduate studies. While it could be argued that all disciplines have their own requirements for academic integrity, there is also potential to explore standards for ethical academic practice between the Health disciplines and other professional education.

\section{References}

Aggarwal, R. Bates, I. Davies, J. \& Khan, I. (2002). 'A Study of Academic Dishonesty Amongst Students at Two Pharmacy Schools'. The Pharmaceutical Journal, 269, 529-533.

Andrews, K.G. Smith, L.A. Henzi, D. \& Demps, E. (2007). 'Faculty and Student Perceptions of Academic Integrity at US and Canadian Dental Schools'. Journal of Dental Education, 71(8), 1027-1039.

Arhin, A.O. (2009). 'A Pilot Study of Nursing Student's Perceptions of Academic Dishonesty: A Generation Y Perspective'. The ABNF Journal, 20(1), 17-21.

Arhin, A.O. \& Jones, K.A. (2009). 'A Multidiscipline Exploration of College Students' Perceptions of Academic Dishonesty: Are Nursing Students Different from Other College Students?', Nursing Education Today, 29, 710-714.

Ashworth, P. Bannister, P. \& Thorne, P. (1997). 'Guilty in Whose Eyes? University Students' Perceptions of Cheating and Plagiarism in Academic Work and Assessment'. Studies in Higher Education, 22(2), 187-203.

Austin, Z. Collins, D. Remillard, A. Kelcher, S. \& Chui, S. (2006). 'Influence of Atitudes Toward Curriculum on Dishonest Academic Behaviour', American Journal of Pharmaceutical Education, 70(3), 1-9.

Australian Health Practitioner Regulation Agency (2010). Student Registrations. Retrieved February 16th, 2011, from http://www.ahpra.gov.au/Registration/StudentRegistrations.aspx

Barnhart, R.K. (1988). Chambers Dictionary of Etymology. Chambers, Edinburgh.

Bilic-Zulle, L. Frkovic, V. Azman, J. \& Petrovecki, M. (2007). 'Is There an Effective Approach to Deterring Students From Plagiarizing?', Science and Engineering Ethics, 14, 139-147.

Bilic-Zulle, L. Frkovic, V. Turk, T. Azman, J. \& Petrovecki, M. (2005). 'Prevalence of Plagiarism Among Medical Students', Croatia Medical Journal, 46(1), 126-131.

Bolin, A.U. (2004). 'Self-Control, Perceived Opportunity, and Attitudes as Predictors of Academic Dishonesty', The Journal of Psychology, 138(2), 101-114.

Bowers, W. (1964). Students' dishonesty and its control in college, Columbia University, New York. 
Brown, B. (1995). 'The academic ethics of graduate business students: a survey', Journal of Education for Business, 70(3), 151-156.

Carroll, J. (2004). Institutional Issues in Deterring, Detecting and Dealing with Student Plagiarism, Imperial College, London.

Chapman, K. (2004). 'Academic Integrity in the Business School Environment: I'll Get by with a Little Help from my Friends', Journal of Economic Education, 23(3), 197-207.

Dick, M. Sheard, J. \& Markham, S. (2001). Is it Okay to Cheat? - The Views of Postgraduate Students, 3, Monash University, Melbourne.

Eastman, J.K. Iyer, R. \& Reisenwitz, T.H. (2008). 'The Impact of Unethical Reasoning On Different Types of Academic Dishonesty: An Exploratory Study', Journal of College Teaching \& Training, 5(12), 7-16.

Elzubeir, M.A. \& Rizk, D.E.E. (2003). 'Exploring Perceptions and Attitudes of Senior Medical Students and Interns to Academic Integrity', Medical Education, 37, 589-596.

Gaberson, K.B. (1997). 'Academic Dishonesty Among Nursing Students', Nursing Forum, 32(3), 14-20.

Gullifer, J. \& Tyson, G.A. (2010). Exploring university students' perceptions of plagiarism: a focus group study. Studies in Higher Education 35(4): 463-481.

Hardigan, P. (2004). 'First- and Third- Year Pharmacy Students' Attitude Toward Cheating Behaviours', American Journal of Pharmaceutical Education, 68(5), Article 110.

Harper, M.G. (2006). 'High Tech Cheating', Nurse Education Today, 26, 672-679.

Honny, J.M. Gadbury-Amyot, C.C. Overman, P.R. Wilkins, K. \& Petersen, F. (2009). 'Academic Integrity Violations: A National Study of Dental Hygiene Students', Journal of Dental Education, 74(3), 251-260.

Hrabak, M. Vujaklija, A. Vodopivec, I. Hren, D. Marusic, M. \& Marusic, A. (2004). 'Academic Misconduct Among Medical Students in a Post-Communist Country', Medical Education, 38, 276-285.

Hutchins, B. \& Cobb, S. (2008). 'When Will We Be Ready for Academic Integrity?', Journal of Dental Education, 72(3), 359-363.

Center for Academic Integrity (2005). Center for Academic Integrity Report, Clemson University, Clemson.

Kenny, D. (2007). 'Student Plagiarism and Professional Practise', Nursing Education Today, 27, 14-18. 
Kiehl, E.M. (2006). 'Using an Ethical Decision-Making Model to Determine Consequences for Student Plagiarism', Journal Of Nursing Education, 45(6), 199-203.

Kisamore, J.L. Stone, T.H. \& Jawahar, I.M. (2007). 'Academic Integrity: The Relationship between Individual and Situational Factors on Misconduct Contemplations', Journal of Business Ethics, 75, 381-394.

Langone, M. (2007). 'Promoting Integrity Among Nursing Students', Journal Of Nursing Education, 46(1), 45-47.

Mallon, T. (1989). Stolen Words: forays into the origins and ravages of plagiarism, Ticknor \& Fields, London.

McCabe, D.L. (2009). 'Academic Dishonesty in Nursing Schools: An Empirical Investigation', Journal Of Nursing Education, 48(11), 614-623.

McCabe, D.L. Trevino, L.K. (1997). 'Individual and Contextual Influences on Academic Dishonesty: A Multi-Campus Investigation', Research in Higher Education, 38, 379-396.

McCabe, D.L. Trevino, L.K. \& Butterfield, K.D. (2001a). 'Cheating in Academic Institutions: A Decade of Research', Ethics \& Behavior, 11(3), 219-232.

McCabe, D.L. Trevino, L.K. \& Butterfield, K.D. (2001b). 'Disonesty in Academic Environments - The Influence of Peer Reporting Requirements', The Journal of Higher Education, 72(1), 29-45.

McCabe, D.L. Trevino, L.K. \& Butterfield, K.D. (2002). 'Honor Codes and Other Contextual Influences On Academic Integrity: A Replication and Extension to Modified Honor Code Settings', Research in Higher Education, 43(3), 357-378.

Mirza, N. \& Staples, E. (2010). 'Webcam as a New Invigilation Method: Students' Comfort and Potential for Cheating', Journal Of Nursing Education, 49(2), 116-119.

Muhney, K. Gutmann, M. Schneiderman, E. DeWald, J. McCann, A. \& Campbell, P. (2008). 'The Prevalence of Academic Dishonesty in Texas Dental Hygiene Programs', Journal of Dental Education, 72(11), 1247-1260.

Park, C. (2003). 'In Other (People's) Words: plagiarism by university students literature and lessons', Assessment \& Evaluation in Higher Education, 28(5), 471-488.

Parker, M. Turner, J. McGurgan, P. Emmerton, L. McAllister, L. Wilkinson, D. Peterson, R. \& Winch, S. (2010). 'The Hard Problem: Assessing Professional Attitudes and Behaviour', Medical Journal of Australia, 193(11/12), 662-4.

Postle, K. (2009). 'Detecting and Deterring Plagiarism in Social Work Students: Implications for Learning for Practise', Social Work Education, 28(4), 351-362. 
Rabi, S.M. Patton, L.R. Fjortoft, N. \& Zgarrick, D.P. (2006). 'Characteristics, Prevalence, Attitudes, and Preceptions of Academic Dishonesty Among Pharmacy Students', American Journal of Pharmaceutical Education, 70(4), 1-8.

Rennie, S.C. \& Rudland, J.R. (2003). 'Differences in Medical Students' Attitudes to Academic Misconduct and Reported Behaviour Across the Years - A Questionnaire Study', Journal of Medical Ethics, 29, 97-102.

Roberts, D. \& Rabinowitz, W. (1992). 'An Investigation of Student Perceptions of Cheating in Academic Situations', Review of Higher Education, 15(2), 179-190.

Roberson, D.W. (2009). 'Using a Student Response System to Reduce Academic Cheating', Nurse Educator, 34(2), 60-63.

Ryan, G. Bonanno, H. Krass, I. Scouller, K. \& Smith, L. (2009). 'Undergraduate and Postgraduate Pharmacy Students' Perceptions of Plagiarism and Academic Honesty', American Journal of Pharmaceutical Education, 73(6), 105-116.

Scanlan, C.L. (2006). 'Strategies to Promote a Climate of Academic Integrity and Minimize Student Cheating and Plagiarism', Journal of Allied Health, 35(3), 179-185.

Simon, C.A. Carr, J.R. McCullough, S.M. Morgan, S.J. Oleson, T. \& Ressel, M. (2004). 'Gender, Student Perceptions, Institutional Commitments and Academic Dishonesty: Who Reports in Academic Dishonesty Cases? ', Assessment \& Evaluation in Higher Education, 29(1), 75-90.

Solomon, M.R. DeNatale, M.L. (2000). 'Academic Dishonesty and Professional Practice: A Convocation', Nurse Educator, 25(6), 270-271.

Staats, S. Hupp, J.M. \& Hagley, A.M. (2008). 'Honesty and Heroes: A positive Psychology View of Heroism and Academic Honesty', The Journal of Psychology, 142(4), 357-372.

Straw, D. (2002). 'The plagiarism of generation 'why not?", Community College Week, 24, 8 July, 4-7.

Teplitsky, P.E. (2002). 'Perceptions of Canadian Dental Faculty and Students About Appropriate Penalties for Academic Dishonesty', Journal of Dental Education, 66(4), 485-491.

Wilkinson, J. (2009). 'Staff and Student Perceptions of Plagiarism and Cheating', International Journal of Teaching and Learning in Higher Education, 20(2), 98-105.

Zobel, J. \& Hamilton, M. (2002). 'Managing Student Plagiarism in Large Academic Departments', Australian University Review, 45(2), 23-30. 